(ICAJ) ISSN : 2549-2314;

Volume : 1; Number 1

\title{
ANALISIS FENOLIK DAN DAYA HAMBAT DAUN BINAHONG (Anredera cordifolia (ten.) Steenis) TERHADAP BAKTERI Eschericia coli DAN Staphylococcus aureus
}

\author{
Hasri', Muhammad Anwar', Marwah Karim² \\ 2 Jurusan Kimia Universitas Negeri Makassar, Jl. Dg Tata Raya. No. 76
}

Email : marwahkarim88@gmail.com

\begin{abstract}
ABSTRAK
Penelitian ini bertujuan untuk menganalisiskandunganfenolikdan mengetahui daya hambat ekstrakdaun binahong (Anredera cordifolia (Ten.) Steenis) terhadapbakteriEschericia coli danStaphylococcus aureus. Ekstraksi daun daun binahong menggunakan pelarut etanol, dan etil asetat. Ekstrak yang diperoleh dianalisis menggunakan spektrofotometer UV-Vis untuk mengetahui kandungan fenolik dan daya hambatnya. Diperoleh kadar fenolik ekstrak etanol sebesar 28,43 mg GAE/g ekstrak, ekstrak etil asetat sebesar 26,47 mg GAE/g ekstrak. Konsentrasi hambat minimum (KHM) ekstrak etanol dan etil asetat terhadap E. coli masing-masing sebesar 8,5\%, dan 7,5\%. Konsentrasi hambat minimum (KHM) ekstrak etanol dan etil asetat terhadap $S$. aureus masingmasing sebesar $8 \%$, dan $9,5 \%$.
\end{abstract}

Kata kunci : Daun Binahong, Fenolik, Anti Bakteri, E. coli, dan S. aureus.

\section{ABSTRACT}

This study aims to analysis the phenolic content and to determine the inhibition of Binahong Leaf Extract (Anrederacordifolia (Ten.)Steenis) toEscherichia coli and Staphylococcus aureus. The extraction of binahong leaf used ethanol and ethyl acetate. Extracts were analyzed by using a UV-Vis spectrophotometer to determine the phenolic content and their inhibiton. The results were obtained phenolic of ethanol extract and ethyl acetate extractwith $28.43 \mathrm{mg} \mathrm{GAE} / \mathrm{g}$ extract and $26.47 \mathrm{mg} \mathrm{GAE} / \mathrm{g}$ extract. A minimum inhibitory concentration (MIC) of ethanol and ethyl acetate extracts to $E$. coli were $8,5 \%$ and $7,5 \%$ respectively. A minimum inhibitory concentration (MIC) of ethanol and ethyl acetate extracts to $S$. aureus were $8 \%$ and $9,5 \%$, respectively.

Keywords: Binahong leaf, Phenolic, AntiBacteria, E. coli and S. aureus.

Salah satu tumbuhan yang 
binahong

\section{(Anredera}

cordifolia

(Ten.)Steenis). Umumnya, binahong dimanfaatkan untuk mengobati berbagai penyakit. Binahong mengandung senyawa aktif yang memiliki aktivitas sebagai antibakteri, antiviral, antifungi, analgesik, dan antiinflamasi (Usha, dkk., 2010). Kandungan senyawa metabolit sekunder pada binahong yaitu flavonoid, terpenoid, steroid, alkaloid, fenol, dan saponin (Katno, dkk., 2006).

$\begin{array}{llr} & \text { Senyawa-senyawa tersebut } \\ \text { dapat dimanfaatkan } & \text { sebagai } \\ \text { penghambat bakteri yang bersifat } \\ \text { patogen. Misalnya saja bakteri }\end{array}$
merupakan bakteri gram negative, dimana bakteri inisecara normal berada di saluran pencernaan bagian bawah dan akan dapat berubah menjadi patogen jika perkembangan kuman di dalam tubuh yang melebihi batas normal, akibat perubahan makanan secara mendadak serta perubahan lingkungan dari panas ke hujan atau sebaliknya.E.coli dapat menyebabkan berbagai penyakit tergantung dari tempat infeksinya, seperti infeksi saluran kemih (ISK) dan diare. Beberapa strain E. coli menyebabkan diare yaitu (EPEC), (ETEC) merupakan penyebab umum diare pada musafir. (EHEC) dihubungkan dengan hemoragic colitis, (EIEC) menyebabkan penyakit mirip shigellosis sedangkan (EAEC) menyebabkan diare yang akut dan kronis(Besung, 2009).

\section{Staphylococcus}

aureus

merupakan bakteri Gram

positifdanmerupakan salah satu bakteri patogen yang ditemukan secara normal di dalam hidung dan kulit manusia. Infeksi dari bakteri ini dapat menyebabkan penyakit kulit, diantaranya yaitu bisul dan jerawat. $S$. aureusjuga dapat mengkontaminasi produk makanan seperti produk daging dan susu, peralatan makanan, serta kondisi lingkungan saat mengolah makanan. Gejala penyakit paling umum akibat mengkonsumsi makanan yang terkontaminasi $S$. aureus yaitu mual, iritasi lambung, mimisan, kram perut dan rasa lemas. Pertumbuhan dari $S$. aureus ini dapat dihambat dengan menggunakan senyawa antibakteri, diantaranya yang diperoleh dari suatu tanaman tertentu (Adejowon, dkk., 2011).

Efektivitas anti bakteri ekstrak senyawa bergantung pada jenis pelarut pengekstrak yang digunakan. Hasil penelitian Sheikh, dkk., (2009) yang telah melakukan ekstraksi menggunakan pelarut $\mathrm{n}$-heksana, etil asetat dan metanol, dilaporkan bahwa perbedaan jenis pelarut ternyata mempengaruhi jumlah ekstrak yang dihasilkan dimana metanol memiliki rendemen paling tinggi, diikuti etil asetat dan n-heksana. Hal tersebut sejalan dengan konsep like dissolve like, dimana senyawa yang bersifat polar akan larut dalam pelarut polar dan 
senyawa yang bersifat non polar akan larut dalam pelarut non polar.

Berdasarkan uraian di atas, perlu dilakukan penelitian untuk mengetahui kandungan fenolik ekstrak etanol, etil asetat dan n-heksana daun binahong dan bioaktivitasnya terhadap bakteri $E$. coli dan $S$. aureus.

\section{METODE PENELITIAN}

\section{Bahan}

Bahan yang digunakan adalah daun binahong (Anredera Cordifolia (Ten.)Steenis), aquadest $\left(\mathrm{H}_{2} \mathrm{O}\right)$, etanol $\left(\mathrm{C}_{2} \mathrm{H}_{5} \mathrm{OH}\right)$, etil asetat $\left(\mathrm{C}_{4} \mathrm{H}_{8} \mathrm{O}_{2}\right)$, asam galat $\left(\mathrm{C}_{7} \mathrm{H}_{6} \mathrm{O}_{5}\right)$, natrium karbonat $\left(\mathrm{Na}_{2} \mathrm{CO}_{3}\right)$, media Nutrient Agar (NA), $\mathrm{NaCl}$ 0,9\%, kertas saring Whatman, aluminium foil, kapas, reagen folin ciocalteu, paper disc, dan isolat bakteri S. Aureusdan bakteri E. coli.

\section{Alat}

Yaituevaporator,neraca analitik, peralatan gelas, penyaring buchner, ose, cawan petri, inkubator, jarum preparat, Buret, stopwatch, spektrometer UV-Vis (Ultraviole-t visible).

\section{Prosedur Kerja}

\section{Ekstraksi}

Sebanyak 500 gram serbuk halus daun binahong dimaserasi dengan etanol, dan etil asetat. Ekstrak hasil maserasi (filtrat) selanjutnya diuapkan pada suhu $40^{\circ} \mathrm{C}$, sampai didapatkan ekstrak kental daun binahong.

\section{Uji Golongan}

Uji senyawa alkaloid dilakukan pada larutan ekstrak dan ditetesi pereaksi Dragendorff pada plat tetes. Terbentuknya endapan cokelat muda sampai kuning menunjukkan bahwa ekstrak tersebut kemungkinan mengandung alkaloid.

Uji terpenoid dan steroid dilakukan pada larutan ekstrak yang ditambahkan 2-3 tetes asam sulfat pekat. Adanya terpenoid ditunjukkan dengan terjadinya warna merah sampai ungu,adanya steroid ditunjukkan dengan terbentuknya warna hijau sampai biru.

Uji flavanoid dilakukan pada larutan ekstrak yang ditambahkan pereaksi besi (III) klorida $\left(\mathrm{FeCl}_{3}\right)$, diamatai warnanya. Warna hijau kekuninganmenunjukkan positif mengandung flavanoid.

Uji senyawa fenolik dilakukan pada larutan ekstrak yang ditambahakan pereaksi $\mathrm{FeCl}_{3} 5 \%$. Terbentuknya warna kehijauan atau biru kehitaman menunjukkan positifsenyawa fenolik.

\section{Analisis Kadar Fenolik}

Ditimbang 0,1 gram sampel ekstrak kemudian dilarutkan sampai 10 $\mathrm{ml}$ dengan akuades. Dipipet sebanyak $0.2 \mathrm{ml}$ larutan ekstrak sampel dan ditambahkan $15.8 \mathrm{ml}$ akuades ditambah $1 \mathrm{ml}$ reagen FolinCiocalteau kocok. Diamkan selama 
10 menit kemudian ditambahkan $3 \mathrm{ml}$ $\mathrm{Na}_{2} \mathrm{CO}_{3} 20 \%$ ke dalam campuran, diamkan larutan selama 2 jam pada suhu kamar. Ukur serapannya dengan spektrofotometer UV pada panjang gelombang serapan maksimum $897 \mathrm{~nm}$.

\section{Uji Bioaktivitas}

Ekstrak kental etanol dan Etil asetat dari daun binahong terlebih dahulu diencerkan dengan pelarutnya masing-masing kemudian sampel tersebut dibuat konsentrasi $7 \%, 7,5 \%$. $8 \%$, 8,5\%, dan $9 \%$ untuk mengukur Konsentrasi Hambat Minimumnya (KHM). kemudian Paper disc diisi dengan sampel yang telah dilarutkan hingga sampel uji pad paper disc tidak menetes.

Pengujian aktivitas antibakteri dilakukan dengan metode difusi agar dengan cara menuangkan sebanyak \pm $20 \mathrm{ml}$ medium NA ke dalam cawan petri dan dibiarkan hingga memadat. Kemudian di tuangkan suspensi bakteri kedalam medium NA tersebut dan diratakan hingga seluruh permukaan medium terdapat bakteri. Meletakan paper disc yang telah berisi sampel uji dan masing-masing pelarutnya sebagai kontrol negatif diatas permukaan medium yang telah terinokulasi bakteri. Kemudian di inkubasi selama $1 \times 24$ jam. Apabila hasil inkubasi menunjukkan zona bening disekitar Uji pendahuluan pada ekstrak etanol danetil asetatdaun binahong bertujuan paper disc, menandakan adanya efek penghambatan larutan uji terhadap bakteri uji. Zona bening yang adamerupakan zona hambat, dapat diukur dengan menggunakan jangka sorong.

\section{HASIL DAN PEMBAHASAN}

Binahong (Anredera cordifolia (Ten.) Steenis) adalah salah satutanaman yang dapat dimanfaatkan untukmengobati banyak penyakit diantaranya,untuk pengobatan luka bakar, penyakittifus, radang usus, sariawan, keputihan,pembengkakan hati, pembengkakanjantung, meningkatkan vitalitas dan daya tahan tubuh (Manoi, 2009).

\section{Uji Golongan}

Uji pendahuluan bertujuan untuk mengetahui senyawa metabolit sekunder yang terkandung dalam ekstrak daun binahong.Hasil ujian pendahuluan selengkapnya dapat dilihat pada Tabel 1.1

Tabel 1.1 Uji Golongan Senyawa Aktif

\begin{tabular}{|c|c|c|}
\hline \multirow{2}{*}{$\begin{array}{c}\text { Senyawa } \\
\text { kimia }\end{array}$} & \multicolumn{2}{|c|}{ Hasil ekstrak } \\
\cline { 2 - 3 } & Etanol & Etil asetat \\
\hline Alkaloid & + & + \\
\hline Terpenoid & - & - \\
\hline Steroid & + & + \\
\hline Flavanoid & + & + \\
\hline Fenol & + & + \\
\hline
\end{tabular}

untuk mendapat informasi awal tentang senyawa metabolit sekunder apa yang 
INDONESIAN CHEMISTRY AND APPLICATION JOURNAL

(ICAJ) ISSN : 2549-2314;

Volume : 1; Number 1

terdapat pada daun binahong.

diperoleh:

Berdasarkan hasil uji pendahuluan

diketahui bahwa pada ekstrak etanol, dan etil asetat daun binahong mengandung senyawa metabolit sekunder Alkaloid, steroid, flavanoid danfenol. Hal ini sejalan dengan penelitian Kurniawandan Wayan (2015), bahwa daun binahong mengandung flavanoid, saponin, steroid, terpenoid, fenol, tanin, dan alkaloid.

\section{Analisis Kadar Fenolik}

Larutan standar asam galat dengan konsentrasi 10 ppm diukur serapannya pada panjang gelombang $500-900 \mathrm{~nm}$. Dari hasil pengukuran diperoleh bahwa nilai serapan paling tinggi berada pada panjang gelombang $897 \mathrm{~nm}$. Berikut adalah grafik hasil pengukuran panjang gelombang maksimum yang

Pada analisis fenolik, ketika sampel ditambah dengan aquades dan reagen Folin-Ciocalteau warna yang dihasilkan masingmasing sampel berwarna kuning, selanjutnya ditambahkan dengan $\mathrm{Na}_{2} \mathrm{CO}_{3} 20 \%$ dihasilkan sampel berwarna biru, kemudian diukur absorbansi



Gambar 1.1 Panjang Gelombang Maksimum

Larutan standar asam galat yaitu 10, 20, 30, 40, dan 50 ppm, kemudian diukur absorbansi menggunakan spektrofotometri UV-Vis.

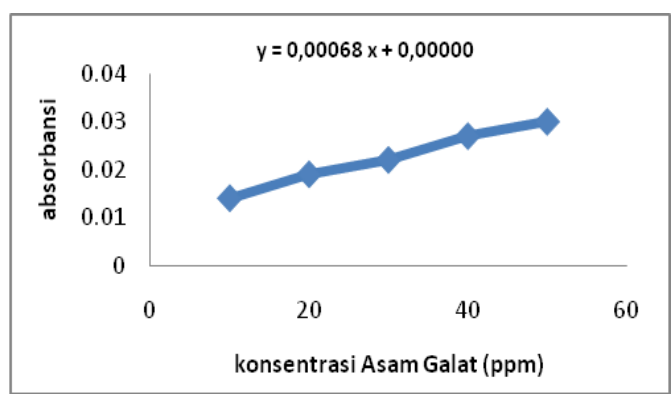

Gambar 1.2 kurva Asam Galat

menggunakan spektrofotometer UV-VIS pada panjang gelombang $897 \mathrm{~nm}$. Kandungan fenolik dinyatakan dalam GAE (Gallic Acid Equivalent) yaitu jumlah kesetaraan miligram asam galat dalam 1 gram sampel, data selengkapnya dapat dilihat pada Tabel 1.3

Tabel 1.3Pengukuran Absorbansi Ekstrak Sampel 
INDONESIAN CHEMISTRY AND APPLICATION JOURNAL

(ICAJ) ISSN : 2549-2314;

Volume : 1; Number 1

\begin{tabular}{|c|c|c|c|c|}
\hline Sampel & Absorbansi & $\begin{array}{l}\text { Rata- } \\
\text { Rata }\end{array}$ & $\begin{array}{c}\text { Konsentarsi } \\
(\mathrm{mg} / \mathrm{L})\end{array}$ & $\begin{array}{c}\text { Konsentrasi ekstrak } \\
\text { sampel x Fp (mg } \\
\text { GAE/g ekstrak) }\end{array}$ \\
\hline \multirow{3}{*}{$\begin{array}{l}\text { Ekstrak } \\
\text { Etanol }\end{array}$} & 0,019 & \multirow{3}{*}{0,0193} & \multirow{3}{*}{28,43} & \multirow{3}{*}{28,43} \\
\hline & 0,020 & & & \\
\hline & 0,019 & & & \\
\hline \multirow{3}{*}{$\begin{array}{l}\text { Ekstrak } \\
\text { Etil asetat }\end{array}$} & 0,018 & \multirow{3}{*}{0,0180} & \multirow{3}{*}{26,47} & \multirow{3}{*}{26,47} \\
\hline & 0,018 & & & \\
\hline & 0,018 & & & \\
\hline
\end{tabular}

\begin{abstract}
Senyawa fenolik dapat
ditetapkan dengan metode Folin-

Ciocalteu. Prinsip dari metode ini adalah reaksi reduksi oksidasi. Reagen

Folin- Ciocalteu merupakan reagen pengoksidasi berupa larutan berwarna kuning. Senyawa fenolik dalam sampel akan dioksidasi oleh molybdotungstate
\end{abstract}

Perbedaan jenis pelarut mempengaruhi jumlah ekstrak yang dihasilkan, pelarut etanol memiliki rendemen paling tinggi, diikuti rendemen ekstrak etil asetatdikarenakan senyawa fenolik merupakan senyawa polar. Tingginya rendemen yang diperoleh pelarut etanol menunjukkan hasil pelarut etanol mampu mengekstrak lebih sar 28,43 mg GAE/ $g$ ekstrak, selanjutnya ekstrak etil asetat sebesar 26,47 mg GAE/g ekstrak. Hal ini dapat terjadi karena senyawa golongan fenol bersifat polar atau semi polar (Hayati dkk, 2010). Flavonoid yang merupakan golongan terbesar dari senyawa golongan fenol bersifat polar sehingga akan banyak terdapat pada ekstrak etanolSementara, pada ekstrak etil asetat dimungkinkan banyak terdapat aglikon flavonoid yang bersifat kurang yang merupakan komponen dari FolinCiocalteu membentuk senyawa berwarna biru. Reaksi antara senyawa fenolik dengan Folin-Ciocalteu berjalan lambat pada suasana asam, sehingga perlu penambahan natrium bikarbonat agar terbentuk suasana basa dan reaksi dapat berjalan lebih cepat (wildan, 2010) banyak komponen bioaktif yang memiliki sifat kepolaran yang lebih tinggi. Hal tersebut dapat terjadi karena etanol memiliki gugus polar yang lebih kuat (Ukhty, 2011). Hasil penentuan kandungan fenolik menggunakan kurva standar asam galat menunjukkan senyawa golongan fenol tertinggi terdapat pada ekstrak etanol sebe polar. Hal ini menunjukkan bahwa semakin polar pelarutmaka fenolik yang diperoleh akan semakin meningkat. Kenaikan tingkat kepolaran pelarut akan meningkatkan kandungan senyawa fenolik yang terekstrak. Senyawa fenolik seperti flavonoid bersifat polar karena strukturnya tersusun dari beberapa gugus hidroksil atau gula. Oleh karena itu, pada umumnya senyawa fenolik lebih cenderung larut dalam pelarut polar seperti etanol. 
Pengujian aktivitas antibakteri dilakukan menggunakan metode difusi agar. Metode ini dipilih karena

\section{Uji Bioaktivitas} sederhana dalam pengerjaannya.

Tabel 1.4 Zona Hambat Pertumbuhan Bakteri E. colidan S. aureus.

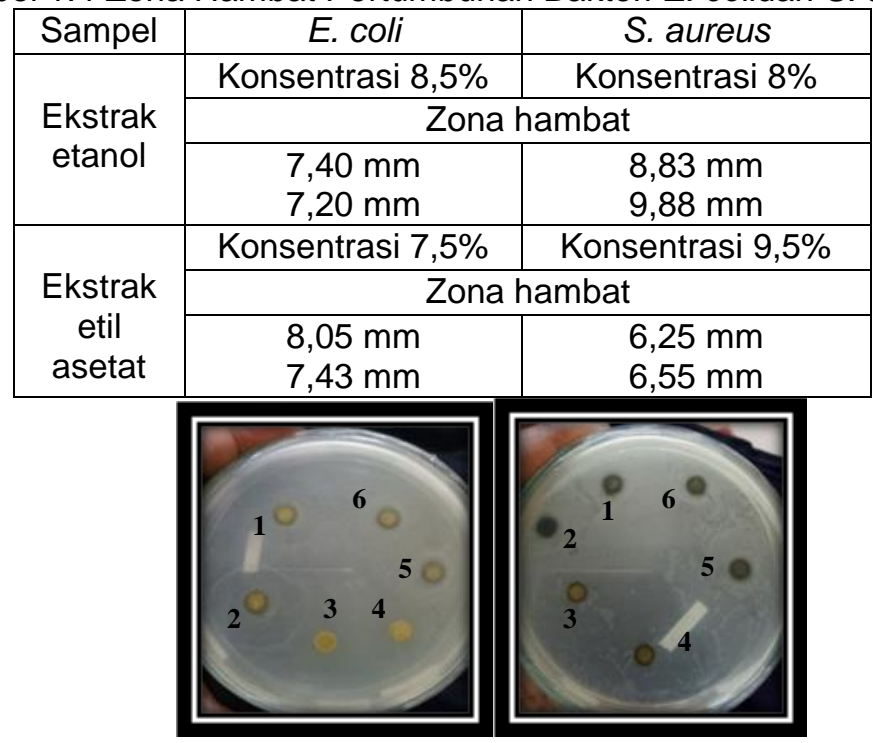

(a) (b)

Ket:

Gambar 1.3bakteri E. coli (a) etanol (b) etil asetat

Untuk (a)

no. $1 \& 2=$ konsentrasi $8,5 \%$

no. $3 \& 4=$ konsentrasi $8 \%$

no. $5 \& 6=$ konsentrasi $9 \%$

Untuk (b)

no. $3 \& 4=$ konsentrasi $7 \%$

no. $1 \& 6=$ konsentrasi $7,5 \%$

no. $2 \& 5=$ konsentrasi $8 \%$

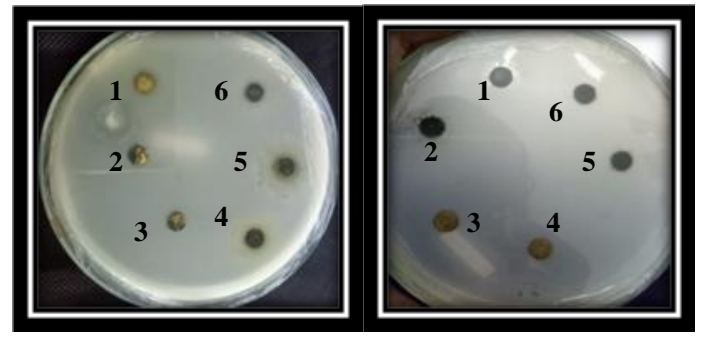

(a)

(b)

Gambar 1.3bakteri E. coli (a) etanol (b) etil asetat

Ket:

Untuk (a) 
no. $2 \& 3=$ konsentrasi $7 \%$

no $1 \& 6=$ konsentrasi $7,5 \%$

no. 4 \& $5=$ konsentrasi $8 \%$

Untuk (b)

no. $3 \& 4=$ konarentrasi $9 \%$

no. $1 \& 2=$ konsentrasi $9,5 \%$

no. $5 \& 6=$ konsentrasi $10 \%$

\section{Berdasarkan hasil pengujian,} aktivitas antibakteri ekstrak etil asetat daun binahong menunjukkan hasil yang terbaik dibandingkan ekstrak etanol terhadap bakteri Eschericia coli diamana konsentrasi hambat minimum (KHM) ekstrak etil asetat sebesar 7,5\%. Sedangkan ekstrak etanol daun binahong menunjukkan hasil yang terbaik dibandingkan ekstrak etil asetat terhadap bakteri Staphylococus aureus dimana konsentrasi hambat minimum (KHM) ekstrak etanol sebesar 8\%.

Hasil yang diperoleh sejalan dengan hasil penelitian Madiah, dkk., (2015) bahwa ekstrak etil kulit buah manggis (Garcinia mangostana) memiliki diameter zona hambat paling tinggi terhadap Aeromonas hydrophila, Edwardsiella tarda dan Saprolegnia sp. dibandingkan ekstrak metanol dan nheksana. Etil asetat merupakan pelarut yang bersifat semipolar. Sifat inilah yang menyebabkan ekstrak etil asetat memiliki dua sifat kelarutan yaitu hidrofilik dan lipofilik. Diketahui pula bahwa suatu senyawa yang mempunyai polaritas optimum seperti etil asetat akan mempunyai aktivitas antimikroba maksimum, karena untuk interaksi suatu Jakarta, Hal : 16-17. senyawa antibakteri dengan bakteri diperlukan keseimbangan hidrofiliklipofilik (Madiah, dkk., 2015).

\section{KESIMPULAN \\ Ekstrak daun binahong memiliki} kandungan fenolik pada ekstrak etanol sebesar 28,43 mg GAE/g ekstrak, ekstrak etil asetat 26,47 mg GAE/ g ekstrak.Aktivitas antibakteri ekstrak etil asetat daun binahong menunjukkan hasil yang terbaik dibandingkan ekstrak etanol terhadap bakteri E. coli dimana konsentrasi hambat minimum (KHM) ekstrak etil asetat sebesar 7,5\%. Sedangkan ekstrak etanol daun binahong menunjukkan hasil yang terbaik dibandingkan ekstrak etil asetat terhadap bakteri $S$. aureus dimana konsentrasi hambat minimum (KHM) ekstrak etanol sebesar $8 \%$.

\section{DAFTAR PUSTAKA}

[1] Usha R., S. Sashidharan, M. Palaniswamy. 2010. Antimicrobial Activity of a Rarely Known Species, Morinda citrifolia L. Journal ofEthnobotanical Leaflets. Vol. 14: 306-311.

[2] Katno, Dyah S., Rohmat M. dan Harto W., 2006, Inventaris TanamanObat Indonesia, edisi VI, Departemen Kesehatan Badan Penelitian dan Pengembangan Kesehatan Balai Penelitian Tanaman Obat, 
(ICAJ) ISSN : 2549-2314;

Volume : 1; Number 1

[3] Besung, I.N.K. 2009. Pengaruh Pemberian Ekstrak Kunyit Pada Anak Babi Yang Menderita ColibacillosisDenpasar:Universitas Udayana.

[4] Adejowon, A.O. David, O. Mary, A.B.J. Bridget, O.F. oyinade, A.A. dan Adebanke, O.A. 2011. Staphylococcus aureus Isolated from Septic Caesaerean Wound at Ile Ife Nigeria: Antibiotics Susceptibility Patterns. International Journal of Medicine Sciences. International Journal of Medicine and Medical Sciences. Vol. 3. No. 5.

[5] Sheikh, T.Z.B. Yong, C.L. dan Lian, M.S. 2009. In vitro antioxidant activity of the hexane and methanolic extracts of Sargassum baccularia and Cladophora patentiramea. Journal of Applied Sciences. Vol. 13 No. 9

[6[ Manoi, F. 2009. Binahong (Anredera cordifolia) (Ten) Steenis Sebagai Obat. JurnalWarta Penelitian Dan Pengembangan Tanaman Industri. Vol. 15 No. 1.

[7] Kurniawan, B. dan Wayan F.A. 2015. Binahong (Cassia Alata L) As Inhibitor Of Escherichia Coli Growth. Artikel J Majority. Vol. 4, No. 4.

[8] Wildan , A.A. 2010.Optimasi Cairan Penyari Pada Pembuatan Ekstrak Daun Pandan Wangi (Pandanus Amaryllifous Roxb) Secara Maserasi Terhadap Kadar Fenolik Dan Flavonoid Total.Momentum, Vol. 6, No. 2 Oktober $2010: 36$ - 41. Sekolah Tinggi IImu Farmasi Yayasan Pharmasi Semarang.

[9] Ukhty N. 2012. Kandungan Senyawa Fitokimia, Total Fenol Dan Aktivitas Antioksidan Lamun (Syringodium/soetifolium). Skripsi. Bogor: IPB.

[10]Hayati E.K., Fasyah A.G., Sa'adah L., 2010, Fraksinasi dan Identifikasi Senyawa Tanin pada Daun Belimbing Wuluh (Averrhoabilimbi L.), Jurnal Kimia, 4(2): 193-200.

[11] Madiah, H., S. Dwi, S. Tajuddin, E. Zulhan. 2015. Aktivitas Antimikroba EkstrakKulit Buah Manggis (Garcinia Mangostana) Terhadap Bakteri Aeromonas Hydrophila,

Edwardsiella Tarda Dan Jamur Saprolegnia Sp.Jurnal Aquacoastmarine. Vol. 8, No. 3. 